\title{
Animation Movies: Are They Entertaining or Threatening for Children?
}

\author{
Nur Hasanah, Eva Octaviana \\ STKIP Kusuma Negara \\ nur.hasanah@stkipkusumanegara.ac.id
}

\section{Article History}

accepted 24/09/2019

approved 01/10/2019

published 01/12/2019

\begin{abstract}
Western animation movies emerge tremendously as an entertainment that can be one of the alternative way for parents to spend their leisure time with their children. The movies are interesting because of their features which has been created with cheerful and colorful nuance, uncanny animation and interesting story. In Indonesia, Western animation movies commonly are rated as all age although some of them should make any parents worried as their contents often consist of violent and sexual packing. This article tries to uncover the phenomenon of these movies and how they can negatively affect children. It uses literature review as a technique to dig in the problem. The negative effects of animation movies have become a threat for children for some prominent reasons. Western animation movies should be considered as one of entertainment media with its consequences and it is better to observe thoroughly before letting the children watch.
\end{abstract}

Keywords: Animation, Effects, Parents, Children

\section{Abstrak}

Maraknya kemunculan film film animasi barat menjadi hiburan yang dinantikan sebagai salah satu alternative yang dipilih oleh para orangtua untuk menghabiskan waktu bersama anakanaknya. Film animasi ini menarik perhatian anak-anak mengingat fitur fiturnya yang memang sengaja diciptakan penuh warna, animasi yang luar biasa, dan cerita yang menarik. Artikel ini mengkaji fenomena film animasi yang membanjiri Indonesia dan efek buruknya untuk anak anak. Teknik pengkajian dalam artikel ini menggunakan teknik kepustakaan. Paparan negatif dari animasi barat menjadi ancaman nyata bagi anak dengan beberapa alasan utama. Dengan adanya artikel ini, diharapkan film animasi barat dapat dipandang sebagai salah satu media hiburan yang perlu dipertimbangkan lebih lanjut sebelum ditonton oleh anak-anak.

Kata kunci: Animasi, Pengaruh, Orangtua, Anak

Social, Humanities, and Education Studies (SHEs): Conference Series https://jurnal.uns.ac.id/shes

p-ISSN 2620-9284

e-ISSN 2620-9292 


\section{PENDAHULUAN}

Saat ini, film menjadi salah satu hiburan bagi masyarakat Indonesia. Menurut Pratista (2008) film dapat didefinisikan sebagai salah satu sarana komunikasi massa yang membawa pesan komunikasi untuk diperlihatkan kepada penonton. Bahkan, jika dilihat dari Undang-undang No 8 tahun 1992 tentang perfilman, film juga dapat dianggap sebagai karya cipta seni dan budaya sehingga menonton film dapat diartikan sebagai salah satu aktifitas untuk mengenal budaya dan seni yang terkandung di dalamnya. Bagi anak-anak, film, terutama film animasi, merupakan salah satu hiburan istimewa bagi mereka. Selain karena mudah didapatkan dengan berbagai macam pilihan media, film animasi juga menyuguhkan fitur yang khas.

Film animasi menjadi daya tarik untuk anak-anak karena fiturnya yang menarik. Film jenis ini menyajikan visual efek penuh warna yang memanjakan mata anak-anak. Lagu-lagu yang nyaman didengar dan diikuti juga menjadi nilai tambah pada film animasi. Animasi mampu menstimulasi daya imajinasi anak. Namun, visual dan pesan yang berefek negatif juga dapat menjadi momok bagi para orangtua. Menurut Klein dan Shiffman (2006), perilaku dan ide anak muda yang negatif dipengaruhi oleh pesan dalam media yang telah mereka dapatkan di masa kecil mereka. Hal ini seharusnya menjadi pertimbangan bagi para orangtua jika mengijinkan anak-anak untuk menonton karena menyaksikan film tidak hanya memiliki nilai hiburan, tetapi juga sekaligus membuat anak mengenal budaya, seni, pesan moral, hingga suatu adegan. Turkmen (2016) mengemukakan bahwa anak anak sulit membedakan apa yang dapat dicontoh atau diikuti di televisi karena kemampuan memisahkan antara dunia nyata dan imajinasi hanya dapat dilakukan saat anak melewati usia 7 tahun.

Indonesia memiliki undang undang yang megatur dalam hal perlindungan anak. Berdasarkan Undang-Undang Republik Indonesia Nomor 23 Tahun 2002 Tentang Perlindungan Anak, anak adalah seseorang yang belum berusia 18 (delapan belas) tahun, termasuk anak yang masih dalam kandungan. Undang- undang ini juga menekankan bahwa perlindungan anak adalah segala kegiatan untuk menjamin dan melindungi anak dan haknya agar dapat hidup, tumbuh, berkembang, dan berpartisipasi, secara optimal sesuai dengan harkat dan martabat kemanusiaan, serta mendapat perlindungan dari kekerasan dan diskriminasi. Peredaran film animasi barat yang kerap menghadirkan visual kekerasan dan seksual serta mengaburkan dunia nyata dan imajinasi dapat mengancam upaya perlindungan anak yang dimaksudkan dalam undang-undang. Visualisasi konten seksual dan kekerasan mengganggu pola pikir anak bahkan anak yang tidak menyaksikan film pun mendapatkan kemungkinan terimbas efek negatif dari mereka yang mengikuti atau meniru adegan negatif tersebut.

Situs berita nasional seringkali melansir berita terkait perilaku siswa siswi yang bermasalah dan berhubungan dengan kekerasan ataupun efek dari konten seksual dari berbagai media seperti film animasi. Salah satunya adalah berita 5 tahun lalu di tahun 2014. Di tahun tersebut, publik digegerkan dengan munculnya video anak Sekolah Dasar swasta di Bukit Tinggi, Sumatera Barat. Dalam video yang berdurasi lebih dari 1 menit tersebut, siswa sekolah dasar memukul temannya. Perilaku agresif dan menyerang ditunjukkan secara jelas dalam video tersebut. Turkmen (2016) menyatakan bahwa kekerasan di sekolah dalam beberapa tahun terakhir dapat terjadi karena anak meniru atau mengikuti tokoh karakter dalam film. Oleh karena itu, para orangtua seharusnya meninjau kembali jika mengajak anak untuk menyaksikan film animasi.

Artikel ini membahas tentang alasan mengapa film animasi barat dapat mengancam anak anak Indonesia. Hal ini penting diketahui mengingat semakin tergerusnya nilai-nilai budaya timur hingga norma agama merupakan bagian dari pengaruh negatif film animasi barat. Tidak banyak orangtua yang menganggap bahwa memperkenalkan film animasi barat di usia dini untuk anak dapat berimbas pada 
perilaku yang tidak lagi memegang nilai budaya timur dan norma agama yang cenderung masih diterapkan di nusantara.

\section{HASIL DAN PEMBAHASAN}

Banyaknya film animasi barat yang tayang di bioskop-bioskop, televisi dan situs berbagi video Youtube di Indonesia dan digemari oleh anak anak seharusnya menjadi hal yang diperhatikan dan disayangkan mengingat masih ada film yang tidak layak tonton untuk anak-anak. Menurut Oyero dan Oyesom (2015), penelitian membuktikan bahwa tidak sedikit orangtua dan anak anak yang percaya kartun memiliki banyak pengaruh positif. Para orangtua seharusnya menjadi benteng utama anak dalam pencegahan paparan hal-hal yang bersifat negatif. Perkembangan teknologi yang menawarkan kemudahan bagi mereka tak jarang menjadi boomerang yang menyerang dan merugikan anak-anak. Di sisi lain, Indonesia memiliki beberapa lembaga yang menangani perlindungan anak seperti Komisi Perlindungan Anak Indonesia dan Lembaga Perlindungan Anak Indonesia. Namun,efek dari paparan film animasi ini tidak menjadi perhatian serius. Seringkali kekerasan terhadap anaklah yang menjadi sorotan utama meskipun pada kenyataannya, paparan konten kekerasan dari film animasi dapat memberikan pengaruh luar biasa pada perilaku anak baik di lingkungan keluarga, sekolah, dan masyarakat, yang kemudian menghasilkan perilaku kekerasan lainnya di kemudian hari.

Perbedaan dua budaya dari negara yang memproduksi film animasi dengan negara yang menikmati film tersebut juga menjadi pertimbangan ketika orangtua menganggap film animasi barat sebagai hiburan anak. Sebagai contoh, Frozen merupakan film animasi yang lekat dengan budaya barat. Adegan keakraban antar lawan jenis seperti yang dilakukan putri Ana, pangeran Hans, dan teman seperjalanannya menunjukkan kebebasan dalam mengekspresikan hal-hal yang seharusnya dilakukan oleh orang dewasa.Adegan ini belum sepenuhnya berterima dalam budaya timur. Terlalu dini jika anak-anak menirukan adegan mesra dalam Frozen. Dewasa sebelum waktunya merupakan ungkapan yang pas untuk menggambarkan perilaku anak anak yang terpapar konten dewasa di usia yang sangat muda.

Dikutip dari Essays, UK (2018), film mempengaruhi manusia dalam banyak hal, mulai dari bahasa, gaya hidup, cara berpakaian, pergaulan, dan hal-hal yang lekat dengan budaya. Anak-anak sebagai generasi penerus jika diperkenalkan budaya barat, mereka meneruskan nilai nilai budaya tersebut. Norma kesopanan dan kesantunan yang menonjol dari budaya timur semakin tergerus akibat hal ini.

Penelitian mengenai pengaruh negatif film telah banyak dilakukan. Yousaf et al (2015) dengan judul Effects of Cartoon Network on the Behaviour of School Going Children. Penelitian ini menggambarkan bagaimana channel televisi Cartoon Network yang menampilkan berbagai macam kartun dengan berbagai judul ternyata memiliki efek buruk bagi perilaku anak sekolah. Habib dan Soliman (2015) telah melakukan penelitian dengan judul Cartoons; Effects in Changing Children Mental Response and Behavior. Penelitian ini melihat tidak hanya efek negatif tetapi juga membuktikan bahwa ada pengaruh positif dari visualisasi kartun di rumah.

Dalam kajian ini, beberapa alasan dapat dikemukakan mengenai mengapa film animasi barat menjadi film yang harus diwaspadai oleh para orangtua Indonesia yang dengan sengaja bahkan rutin mengajak anak-anak untuk menyaksikan film animasi. Alasan ini penting diketahui untuk meningkatkan kewaspadaan terhadap ancaman nyata dari sebuah film animasi bagi anak. 


\section{Alasan Animasi Mengancam Anak}

Yousaf et al (2015) mengungkapkan bahwa kartun mempengaruhi anak secara psikologis. Hasil penelitiannya telah menunjukkan bahwa pengaruh negatif tidak sebatas hanya perilaku tetapi juga tutur kata yang meninggalkan nilai kesantunan.

Ada beberapa alasan mengapa animasi mengancam anak Indonesia. Dari peran Lembaga Sensor Film yang belum maksimal hingga visual dalam film yang menjadi contoh bagi anak sehingga contoh visual yang tidak mendidik pun tidak terlepas dari perhatian.

\section{Peran LSF Yang Belum Maksimal}

Sebelum dapat tayang, film di Indonesia harus melewati uji kelayakan tayang yang diadakan oleh Lembaga Sensor Film (LSF). Berdasarkan PP no 7 tahun 1994, LSF memiliki fungsi, tugas, dan kewenangan yang harus dijalankan. Salah satu fungsi LSF adalah melindungi masyarakat dari kemungkinan dampak negatif yang timbul dalam peradaban, pertunjukan dan atau penayangan film dan reklame film yang tidak sesuai dengan dasar dan tujuan pefilman indonesia.

Dilihat dari fungsi ini, sudah seharusnya seluruh film yang tayang di Indonesia sudah lulus kelayakan. Sayangnya, beberapa film berkategori sebagai film animasi seperti Frozen dan Despicable Me 3 telah melewati uji kelayakan oleh LSF dan dinyatakan sebagai film yang memiliki klasifikasi untuk semua usia. Berbeda dengan LSF, Dunia perfilman barat khususnya di Amerika, memiliki Classification and Rating Administration yang khusus memberikan rating pada film film yang beredar dengan klasifikasi General Audiences (G), Parental Guidance (PG), Parents strongly cautioned (PG-13), Restricted (R), dan No one 17 and under admitted (NC17). CARA menetapkan kedua film tersebut sebagai film dengan klasifikasi usia Parental Guidance (PG). PG merupakan rating yang menghimbau orangtua untuk memberikan pendampingan bagi anak anaknya saat menonton. Perbedaan penentuan klasifikasi usia pada kedua film tersebut kemudian menimbulkan pertanyaan sederhana, bagaimana mungkin jika di negara produksi (di Amerika), film tersebut merupakan film yang memerlukan pendampingan orangtua sedangkan di Indonesia, Frozen dan Despicable Me 3 boleh ditonton oleh kalangan semua usia?

LSF merupakan lembaga yang memiliki wewenang untuk menentukan klasifikasi usia untuk semua film yang akan tayang di Indonesia khususnya bioskop dan televisi. Peraturan Pemerintah RI No 18 Tahun 2014 Tentang Lembaga Sensor Film memperjelas bahwa penggolongan usia penonton bagi suatu film dimaksudkan untuk melindungi masyarakat dari dampak negatif dalam rangka pembinaan keluarga. Keluarga dalam hal ini tentu saja terkait pengaruh film terhadap karakter anak dalam keluarga yang menjadi perhatian utama para orangtua.

Jika mengakses situs resmi LSF yaitu www.Isf.go.id, masyarakat Indonesia dapat mengetahui penentuan golongan usia penonton pada setiap film yang tayang. Sebagai contoh beberapa film animasi seperti Frozen dan Despicable Me 3 merupakan film yang memiliki golongan usia penonton untuk semua usia menurut LSF. Dalam peraturan pemerintah yang telah disebutkan di atas, pada pasal 33 menjelaskan bahwa salah satu hal yang harus diperhatikan dalam film dengan golongan usia semua umur adalah berisi tema, judul, adegan visual serta dialog dan atau monolog yang sesuai usia dan tidak merugikan perkembangan dan kesehatan fisik dan jiwa anak anak. Sayangnya, pengawasan di bioskop masih sangat minim. Seringkali film yang megandung konten seksual dan adegan kekerasan mudah untuk ditonton oleh anak-anak di bioskop. LSF beberapa kali telah mendapatkan kritik dari masyarakat terkait perannya sebagai garda terdepan menjaga agar tidak ada paparan negatif dari film yang beredar pada anak-anak Indonesia. 


\section{Terulangnya Fenomena Boneka Barbie}

Disney sebagai salah satu produsen film animasi terbesar mengilustrasikan sosok seorang putri cantik yang memiliki bentuk tubuh yang tidak proporsional. Seperti halnya fenomena Barbie yang pernah menjadi kekhawatiran di masa lalu. Boneka Barbie yang diciptakan pada tahun 1959 menjadi idola bagi anak-anak pada masanya meskipun memiliki proporsi tubuh yang tidak baik untuk kesehatan. Menurut Dittmer, Halliwell and Ive (2006),karena telah menjadi ikon, boneka seperti Barbie diam-diam telah menjadi panutan, setidaknya bagi para gadis muda. Hal ini dapat dihubungkan dengan fenomena Frozen yang baru-baru ini menjamur di kalangan anak-anak gadis, termasuk anak-anak usia balita. Anak-anak yang mengidolakan Putri Elsa ataupun Anna akan menganggap konsep cantik dapat diartikan memiliki bentuk tubuh dengan pinggang yang sangat kecil. Fenomena pinggang sangat kecil ini juga sudah beberapa kali dicontoh oleh kalangan wanita dewasa yang memang sejak kecil telah mengidolakan Barbie sejak dulu, sehingga tidak mustahil, di masa depan akan bermunculan sosok wanita dewasa yang tampil menyerupai putri Elsa atau Anna karena sejak kecil terobsesi dengan film putri Disney, contohnya Frozen.

\section{Adegan Visual Intim (Sexual Content)}

Beberapa adegan yang menunjukkan keintiman antara Putri dan Pangeran ataupun tokoh pria dan wanita masih terlalu dini untuk disaksikan oleh anak-anak. Penelitian telah dilakukan oleh Ross O'Hara dan beberapa peneliti di bidang psikologi dan dipublikasikan di Psychological Science,jurnal The Association for Psychological Science. Hasil penelitian menunjukkan beberapa hal sebagai berikut:

1. Film memiliki lebih banyak pengaruh daripada TV atau musik.

2. Hasil survey yang dilakukan tim O'Hara pada film dari tahun 1950-2006 menunjukkan bahwa $68 \%$ dari film dengan golongan usia $\mathrm{G}$ atau Semua Usia dan $82 \%$ film dengan kategori usia Parental Guidance (dengan pendampingan orangtua) mengandung konten seksual.

Efek dari seksual konten ini pun telah diteliti. Paparan konten ini ternyata membantu promosi pergaulan bebas dan anak-anak terancam lebih dini mempraktekkan hal-hal yang telah dianggap biasa dalam film, termasuk adegan intim.

\section{Adegan Kekerasan}

Kekerasan adalah situasi yang membahayakan individu dan grup secara psikologis, sosial dan fisik. Penelitian mengenai kekerasan pada anak juga telah dilakukan dalam berbagai perspektif dan media. Jika dilihat dari perspektif kelompok apa saja yang mudah terpapar kekerasan dengan media televisi telah dilakukan oleh Josephson (1995) Johnson, Cohen, Smailes, Kasen, dan Brook (2002) dan Paquette (2003). Penelitian tersebut melihat bagaimana paparan kekerasan telah terjadi melalui media televisi. Saat penelitian dilakukanpun, media yang mengandung paparan kekerasan masih terbatas, tidak seperti saat ini yang memiliki media bervariasi yaitu televisi, bioskop, handphone, dan internet sehingga ancaman efek buruk dari adegan kekerasan pada film animasi yang beredar melalui berbagai media harus menjadi hal yang perlu diperhatikan para orangtua.

Terlepas dari media apapun itu, Penelitian oleh Turkmen (2016) telah membuktikan bahwa visualisasi kekerasan telah banyak ditunjukkan dalam berbagai film animasi berupa penculikan, pemukulan, pelecehan, pencurian, percobaan pembunuhan, hingga pembunuhan. Bentuk kekerasan juga dapat secara fisik dan verbal. Paparan kekerasan fisik lebih dominan jika dibandingkan dengan kekerasan verbal. Jika anak belum mampu membedakan antara dunia nyata dan imajinasi, paparan adegan kekerasan ini sangat membahayakan. Bukan hal yang mustahil bagi anak untuk menirukan adegan dengan mengajak teman-temannya tanpa memahami bahaya dibalik perbuatan tersebut. 


\section{SIMPULAN}

Proses pembelajaran mata kuliah bahasa Inggris tidak dapat dipisahkan dengan Film animasi diberikan klasifikasi usia yang seharusnya bertujuan untuk membantu para orang tua dalam memilih film yang ingin disaksikan oleh anak mereka. Indonesia telah menerapkan sensor film dengan menentukan kategori usia pada setiap film animasi yang tayang. Sayangnya, klasifikasi usia yang sudah ada di Indonesia masih harus ditinjau kembali karena konten cerita dan visual yang mengandung kekerasan atau memiliki konten seksual tidak menjadi perhatian utama saat menentukan klasifikasi usia. Visualisasi konten seksual dan kekerasan dalam film animasi memiliki efek yang mengkhawatirkan bagi anak. Visualisasi konten seksual mempromosikan pergaulan bebas yang tidak sesuai dengan budaya Indonesia yang mayoritas penduduknya masih memegang erat norma agama sedangkan visualisasi konten kekerasan berpengaruh besar terhadap perilaku anak..

\section{DAFTAR PUSTAKA}

Dittmar, Helga, Emma Halliwell and Suzanne Ive. (2006): "Does Barbie make girls want to be thin? The effect of experimental exposure to images of dolls on the body image of 5 to 8 year old girls." Developmental Psychology 42.2 283-292. Diakses dari https://www.researchgate.net/publication

Fisch, S. M., Truglio, R. T., \& Cole, C. F. (2009). The impact of Sesame Street on preschool children: A review and synthesis of 30 years' research. Media Psychology, 1(2), 165- 190

Himpunan Peraturan Tentang Transaksi Elektronik, Pornografi, Penyiaran, Film dan Pers Tahun 2012-2013.(2012). Jakarta: PT Tamita Utama.

Habib, K., Soliman, T. 2015. Cartoons' Effects in Changing Children Mental Response and Behaviour. Open Journal of Social Sciences, 3, 248-264.

(https://www.filmratings.com)

O'Hara, R.(2012). Exposure to Sexual Content in Popular Movies Predicts Sexual Behavior in Adolescence. Diakses 20 September 2019, dari https://www.psychologicalscience.org/news/releases/exposure-to-sexual-contentin-popular-movies-predicts-sexual-behavior-in-adolescence.html

Oyero, OS and Oyeso, KO. (2014). Perceived Influence of Television Cartoons on Nigerian Children's Social Behaviour. Estudos em Communicaca. 17, 93-116

Kalayci, S. (2012). "A Journey to Bilingualism" A Case Study of German-Turkish Bilingual Family. Educational Process: International Journal, 1(1-2), 29-38.

Kirsh, S. J. (2006). Cartoon Violence and Aggression in Youth. Aggression and Violent Behaviour, 11, 547-557.

Pratista, Himawan. (2008). Memahami Film. Yogyakarta: Homerian Pustaka

Rogers, Mary.(1998). Barbie Culture, London: Sage Publications Ltd.

Turkmen, M. (2016). Violence in Animated Feature Films: Implications for Children. Educational Process: International Journal, 5(1), 22-37. Diakses dari https://pdfs.semanticscholar.org

Weissman, Kristin. (1999). Barbie: The Icon, The Image, The Ideal, United States: Universal Publishers.

Yousaf,Z. Shehzad,M and Hassan, SA. (2015). Effects of Cartoon Network on the Behaviour of School Going Children (A Case Study of Gujrat City), International Research Journal of Interdisciplinary and multidisciplinary Studies. Volume 1, Issue 1, Page No. 173-179

Essays, UK. (November 2018). Impact of Movies on Society. Retrieved from https://www.ukessays.com/essays/film-studies/influence-of-movies-to-societyfilm-studies-essay.php?vref=1 